\title{
LA MIRADA DE GERDA TARO Y ROBERT CAPA EN VALENCIA DURANTE EL SEGUNDO CONGRESO INTERNACIONAL DE ESCRITORES PARA LA DEFENSA DE LA CULTURA
}

\author{
Lorna Beatriz Arroyo Jiménez \\ Universidad Internacional de La Rioja
}

Resumen: El Segundo Congreso Internacional de Escritores para la Defensa de la Cultura celebrado en Valencia durante la Guerra Civil Española desvió la mirada mundial hacia la ciudad. El acontecimiento atrajo a un gran número de intelectuales y corresponsales extranjeros, entre ellos los fotoperiodistas Gerda Taro y Robert Capa, que documentaron juntos el acto de inauguración el día 4 de julio de 1937. A través del análisis pormenorizado de una fotografía realizada por Gerda Taro a la escritora Anna Seghers, este artículo realiza una lectura del contexto los días en los que Valencia se convirtió en el centro mundial de la intelectualidad antifascista.

Palabras clave: Gerda Taro; Robert Capa; Anna Seghers; Valencia; Guerra Civil Española; Análisis fotográfico.

The look of Gerda Taro and Robert Capa during the Second International Congress of Writers in Defense of Culture

Abstract: The Second International Congress of Writers for the Defense of Culture, celebrated in Valencia during the Spanish Civil War diverted the global look to this city. The event attracted many intellectuals and foreign correspondents, including the photojournalists Gerda Taro and Robert Capa, who documented together the opening ceremony on July 4, 1937. Through detailed analysis of a particular photograph taken by Gerda Taro to the writer Anna Seghers, this article reviews the context the day that Valencia was the world center of anti-fascist intellectuals.

Key words: Gerda Taro; Robert Capa; Anna Seghers; Valencia; Spanish Civil War; Analysis photographic.

\section{INTRODUCCIÓN}

La Guerra Civil Española inauguró la era de la comunicación visual de masas gracias al uso masivo de la fotografía en prensa. La evolución de las cámaras fotográficas hacia la miniaturización, las ópticas más luminosas y el uso de emulsiones sensibles favorecieron la precisión del documento gráfico y, con ello, su difusión masiva en los periódicos y revistas gráficas, en aquellos momentos en auge. Este hecho convirtió a la guerra de España en gran objeto de atención internacional, y al reporterismo gráfico en un fenómeno social, informativo y propagandístico de primer orden.

Sin duda, uno de los mayores actos de propaganda organizado en España durante el trienio de la guerra fue el encuentro de intelectuales que tuvo lugar durante el Segundo

Data de recepció: 31 de juliol de 2014 / Data d'acceptació: 29 d'octubre de 2014. 
Congreso de Escritores para la Defensa de la Cultura, un evento organizado por la Alianza de Intelectuales Antifascistas al que también asistieron algunos de los periodistas y fotógrafos más influyentes de la época. La prensa difundió el trabajo de estos corresponsales por todo el mundo, y la noticia del acontecimiento convirtió a la ciudad de Valencia en la capital internacional de la intelectualidad antifascista.

El presente artículo examina este momento a través del análisis pormenorizado de una fotografía realizada por Gerda Taro a la escritora alemana Anna Seghers durante su intervención en este congreso (Fig. 1), cuya inauguración documentaron conjuntamente Taro y Capa en el Salón de Actos del Ayuntamiento de Valencia cuando la ciudad ostentaba la capitalidad oficial del Estado. El estudio parte de la hipótesis de que la fotógrafa asumió un papel activista ante la situación española al tratar de influir en la opinión pública mediante la publicación de fotografías como la seleccionada para realizar este estudio.

Las colecciones de los principales periódicos que hemos examinado se encuentran en la Hemeroteca Municipal de Valencia y la Hemeroteca Municipal de Madrid. Detallamos también a continuación los bancos de imágenes o archivos fotográficos de los que proceden las fotografías originales de Taro y Capa examinadas para este trabajo:

El International Center of Photography de Nueva York (ICP), que posee el mayor conjunto de obra de ambos fotógrafos en diferentes soportes -negativos, copias índice y ampliaciones de época-, incrementado en el año 2007 con casi 4.500 negativos inéditos descubiertos en México sobre el tema de la Guerra Civil Española y pertenecientes a Gerda Taro, Robert Capa y David Seymour "Chim". Concretamente, el fondo alberga las siguientes series de Valencia: la instrucción de los milicianos y milicianas en la ciudad, el seguimiento del Segundo Congreso Internacional de Escritores Antifascistas, los bombardeos en Valencia, el entierro del general Pavol Lukács, algunos retratos de Dolores Ibárruri La Pasionaria y una serie dedicada a la vida civil en la calle y los desfiles militares. El mayor número de obra de este fondo contextualizada en Valencia pertenece a Gerda Taro ${ }^{1}$.

Los Archivos Nacionales de París (ANP) custodian más de 2.500 copias índice pertenecientes a Gerda Taro, Robert Capa, David Seymour "Chim” sobre la Guerra Civil Española. Algunas de estas fotografías son copias por contacto de los negativos descubiertos en La maleta mexicana ${ }^{2}$.

Y el Archivo Histórico del Partido Comunista Español (PCE), que alberga 120 negativos en $35 \mathrm{~mm}$ atribuibles a Robert Capa y Gerda Taro, y algunas copias de época -primera tirada o vintage - relativas al Segundo Congreso Internacional de Escritores Antifascistas en Valencia y los bombardeos a la ciudad durante 1937. De este fondo procede la fotografía de Gerda Taro analizada en profundidad.

\footnotetext{
${ }^{1}$ No ha sido hasta fechas recientes que la obra de Gerda Taro ha comenzado a ser objeto de interés científico. Al respecto, puede nombrarse la investigación de Lorna B. Arroyo Jiménez, el primer trabajo que estudia en profundidad la obra de esta fotógrafa (Arroyo, 2010).

${ }^{2}$ La Maleta Mexicana es como se ha dado a llamar al conjunto de tres cajas de cartón en las que permanecieron guardados y desaparecidos en México durante más de siete décadas los más de 4.000 negativos de Robert Capa, Gerda Taro y David Seymour "Chim" sobre la Guerra Civil Española. El material se encuentra actualmente en el ICP de Nueva York.
} 


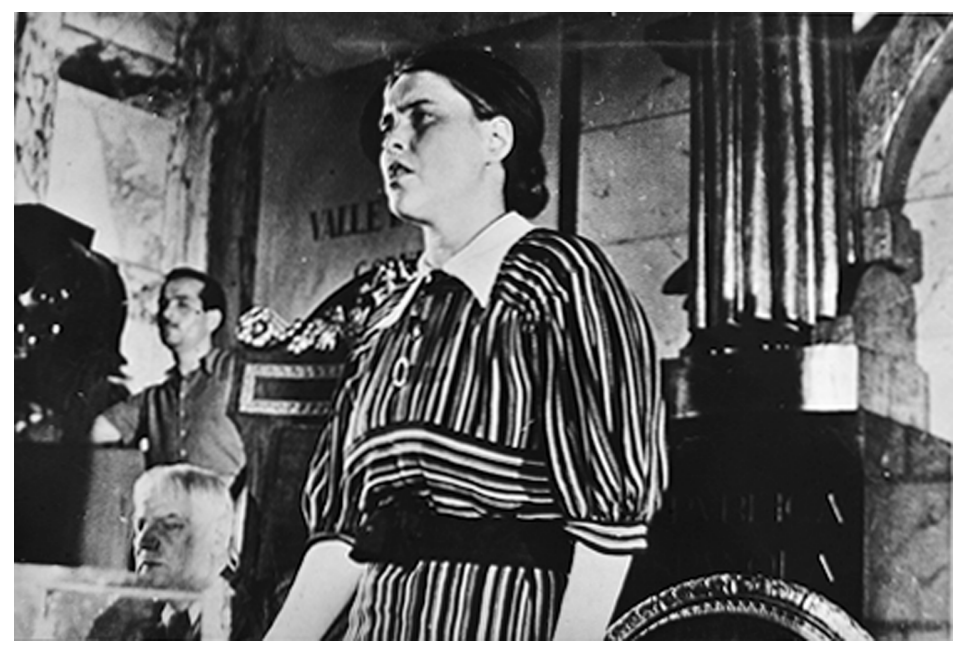

Fig. 1. Fotografía de Anna Seghers durante su intervención en el Segundo Congreso de Escritores Antifascistas para la Defensa de la Cultura. Valencia, 5 de julio de 1937. Fotografía de Gerda Taro. Archivo Histórico del Partido Comunista Español (PCE).

\section{ANÁLISIS FOTOGRÁFICO: ESTUDIO DEL CASO DEFINIDO}

Las razones del valor de una fotografía histórica pueden ser múltiples, no excluyentes entre sí, y una imagen puede tener un valor periodístico, estético, sociológico o documental, como ocurre con la fotografía objeto de este estudio. Sin embargo, como advierte Umberto Eco en su ensayo Los límites de la interpretación, "todo texto puede interpretarse infinitamente" (Eco, 1990: 357), lo que podría suponer un riesgo en el trabajo de cualquier análisis. Los cuatro niveles que se distinguen a continuación ${ }^{3}$ nos permitirán profundizar en los principales aspectos de la imagen y a la vez establecerán límites ante cualquier posibilidad de deriva interpretativa o ausencia de dirección en el recorrido analítico.

\subsection{Nivel contextual}

En este primer nivel de la metodología de análisis tenemos por objetivo facilitar la competencia lectora mediante la información ofrecida sobre el momento concreto que contextualiza a la imagen, los datos técnicos y de conservación de la misma y algunas cuestiones de interés sobre su autor empírico. Así pues, podemos comenzar destacando que nos hallamos ante una fotografía realizada por Gerda Taro el 5 de julio de 1937 en la Sala de Sesiones del Ayuntamiento de Valencia. La imagen la protagoniza la escritora alemana Anna Seghers durante su intervención en el Segundo Congreso Internacional de Es-

${ }^{3}$ El presente estudio utiliza el método de análisis fotográfico desarrollado por el catedrático Javier Marzal y el grupo de investigación ITACA-UJI (Marzal, 2007: 178-229). 
critores Antifascistas para la Defensa de la Cultura, un acto inaugurado el domingo 4 de julio de 1937 en Valencia por el presidente del gobierno republicano Juan Negrín, quien junto a José Giral, Julián Zugazagoitia y Bernardo Giner de los Ríos, compusieron la mesa presidencial de la cámara ${ }^{4}$.

Este encuentro de intelectuales fue precedido por el Primer Congreso Internacional de Escritores para la Defensa de la Cultura celebrado en el Palais de la Mutualité de París entre el 21 y el 25 de junio de 1935, donde tuvo lugar la creación de una Asociación Internacional de Escritores para la Defensa de la Cultura (AIDC), cuyo Comité Internacional estuvo compuesto por doce reputados escritores antifascistas, entre los que se encontraba el español Ramón María del Valle-Inclán. La Alianza de Intelectuales Antifascistas se creó como sección española de la Asociación Internacional, y fue la encargada de promover este segundo evento a fin de discutir la actitud de los intelectuales ante la guerra, pero también con el objetivo de centralizar la atención internacional en la causa republicana. El Segundo Congreso Internacional de Escritores Antifascistas fue la actividad más importante organizada por la Alianza a nivel internacional; también constituyó el mayor acto de propaganda intelectual realizado por el Ministerio de Instrucción Pública y Bellas Artes durante la Guerra Civil Española (Aznar, 2007: 89).

Si bien la petición formal del encuentro fue realizada antes de la guerra, su confirmación rotunda llegó en noviembre del mismo año cuando Romain Rolland, Heinrich Mann y André Malraux, entre otros, confirmaron a la Alianza la celebración de un nuevo evento en España. Este segundo congreso ha permanecido en el imaginario colectivo como uno de los eventos culturales de mayor significación histórica gracias a la participación de hombres y mujeres de todo el mundo que representaron a las generaciones más activas intelectualmente de la época (Aznar, 2009). En él intervinieron más de un centenar de escritores antifascistas. Entre ellos figuraron los ingleses Ralph Bates, Stephen Spender y Silvia Towsend Warner; los alemanes Heinrich Mann, Bertolt Brecht y Kurt Stern; los soviéticos Mijaíl Koltsov, Ilya Ehrenburg y Alexéi Tolstói; los franceses Claude Aveline, Louis Aragon, Julien Benda, André Malraux y Tristan Tzara; el noruego Nordalh Grieg; el argentino Cayetano Córdova Iturburu; el mexicano Octavio Paz, los cubanos Alejo Carpentier y Nicolás Guillén; el chileno Pablo Neruda; los españoles Rafael Alberti, $\mathbf{M}^{\mathrm{a}}$ Teresa de León, José Bergamín, Antonio Machado, Ramón J. Sender y, concretamente, los valencianos Eric Navarro, Bernat Artola y Carles Salvador, que fue quien se dirigió en su lengua a los intelectuales de todo el mundo (Aznar, 2007: 90-91).

El planteamiento central de las conferencias fue el de justificar la resistencia popular contra el fascismo, algo que venía a expresar la nueva política cultural impulsada por los Partidos Comunistas. Esto explica que, aunque la presidencia se repartió entre el azañista Ricardo Baeza y el católico José Bergamín, la ideología comunista fuera el peso determinante del acto.

El congreso fue de recorrido itinerante. Se inició en Valencia el 4 de julio, pero el día 6 , en víspera de la batalla del Jarama, los participantes se trasladaron a Madrid, seguidamente a Barcelona, para regresar nuevamente a Valencia el día 10 y concluir en París los días 16 y 17. Aunque su inauguración estaba inicialmente prevista en Madrid y recorrió

${ }^{4}$ El martes 6 de julio de 1937 El Mercantil Valenciano publicó una fotografía de la mesa presidencial donde aparecen los ilustres citados. Doce días después, la revista semanal Crónica publicó esta misma imagen junto a otra fotografía realizada por Luis Vidal donde aparecen Gerda Taro, Robert Capa y muchos de los asistentes al congreso en la misma Sala de Sesiones del Ayuntamiento de Valencia (Fig. 7). 
diferentes ciudades, el Segundo Congreso Internacional de Escritores Antifascistas se encontró claramente vinculado a la capital del Turia por su condición de sede del gobierno republicano desde noviembre de 1936.

El detonante de este encuentro fue, por tanto, el de hacer un llamamiento para la defensa de la cultura y de la libertad de los pueblos. Todos los escritores extranjeros que se trasladaron a España en plena guerra civil para asistir al evento expresaron su solidaridad con la República Española y su rechazo contra la política de no-intervención practicada por la mayoría de los gobiernos democráticos.

Este también fue el caso de los fotógrafos extranjeros Gerda Taro y Robert Capa, que documentaron conjuntamente la inauguración del acto. Gerda y Capa se habían conocido en París meses antes del inicio de la Guerra Civil Española. Hasta entonces Robert Capa respondía al nombre de Endre Ernő Friedmann, y el cambio de nombre formó parte de una estrategia ideada por ambos para incrementar el precio de sus trabajos mediante el uso común del nombre ficticio Robert Capa. Pero, a medida que la guerra avanzaba, la fotógrafa comenzó progresivamente a firmar sus trabajos de manera independiente con el sello "Photo Taro", dado el problema de atribución de imágenes que generaba el uso del sello común. No obstante, pese a este distanciamiento profesional, evidenciado mediante el uso de firmas diferentes, lo cierto es que la pareja nunca cesó definitivamente en sus colaboraciones, como demuestran la doble cobertura de la inauguración del congreso en Valencia y el siguiente trabajo proyectado -que no llegaría a realizarse- para documentar juntos el conflicto chino-japonés.

Precisamente, para ultimar los preparativos de este inminente proyecto en China, ambos tenían previsto regresar a París al día siguiente de la inauguración del congreso. Sin embargo, fue Capa quien viajó en solitario a la capital francesa el 5 de julio mientras Gerda prolongaba su estancia en Valencia.

Todo indica que Taro sentía especial interés por esta ciudad de gran importancia en la geografía de la Guerra Civil Española. Durante la primavera de 1937 ya la había retratado con los abundantes símbolos que proclamaban la resistencia contra el fascismo (Mendelson, 2011). Aquí también se enmarca su trabajo sobre los efectos de los bombardeos sobre la población civil y las series de la vida urbana de una misma ciudad que parecía ajena a la guerra. En este caso, resultan especialmente interesantes sus imágenes de la vida cívica, unas fotografías que captaron el bullicio de la urbe en lo que parece un paseo de la fotógrafa por el centro de Valencia y donde la alegría de la gente, el comercio y los símbolos propagandísticos cobran especial protagonismo (Figs. 2, 3 y 4). Al parecer, Taro consideraba que España aún necesitaba el apoyo de los medios de comunicación para la victoria republicana y por ello decidió quedarse en Valencia junto a los congresistas, a los que luego acompañó en sus sesiones de Madrid (Fig. 19). En esos momentos se inició una nueva ofensiva republicana en Brunete, al oeste de la capital española, y la fotoperiodista obtuvo el permiso solicitado a Ce Soir para documentarla hasta el final, pero murió durante esta batalla. Luego, fue en Valencia, en la inauguración del Segundo Congreso de Escritores Antifascistas, donde tuvo lugar el último encuentro entre Capa y Taro, ya que la fotógrafa, que compaginó el seguimiento de los congresistas con la cobertura de la Batalla de Brunete, perdió la vida el 26 de julio de 1937. Tres días después la escritora Ma Teresa de León la recordaba en la publicación El Mono Azul mediante la crónica de su muerte, 

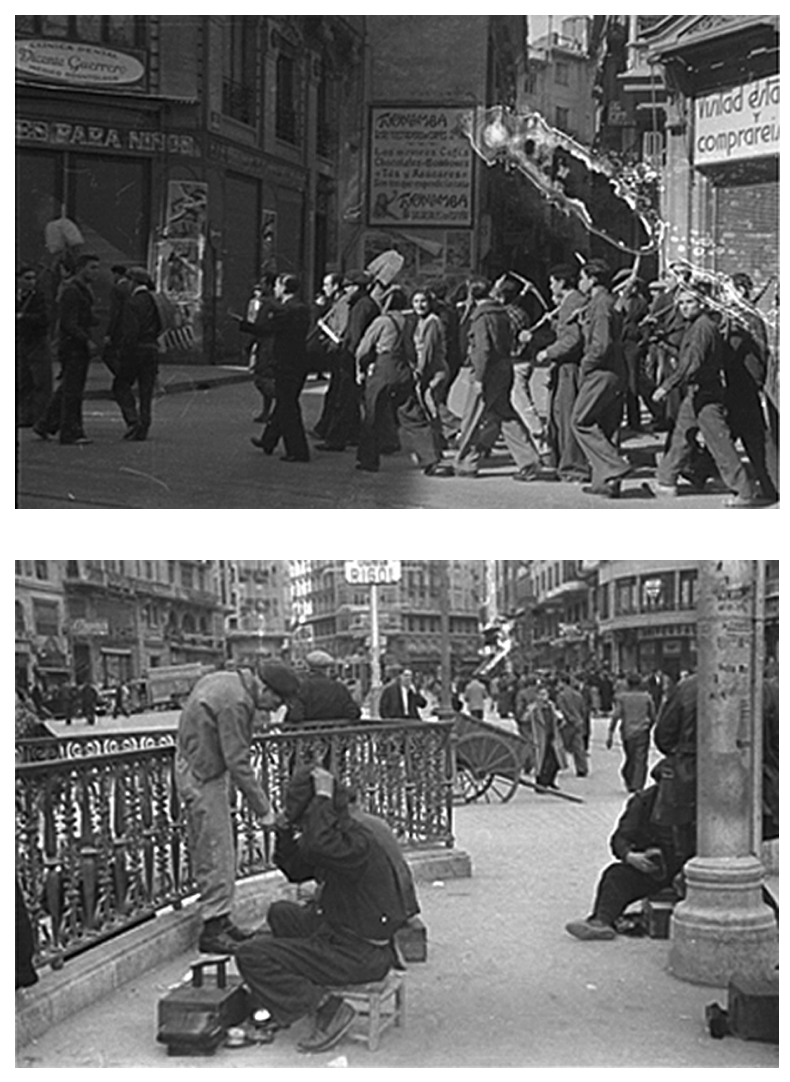

Figs. 2 y 3. La vida en el centro de Valencia durante la primavera de 1937. Fotografías de Gerda Taro (C) ICP.

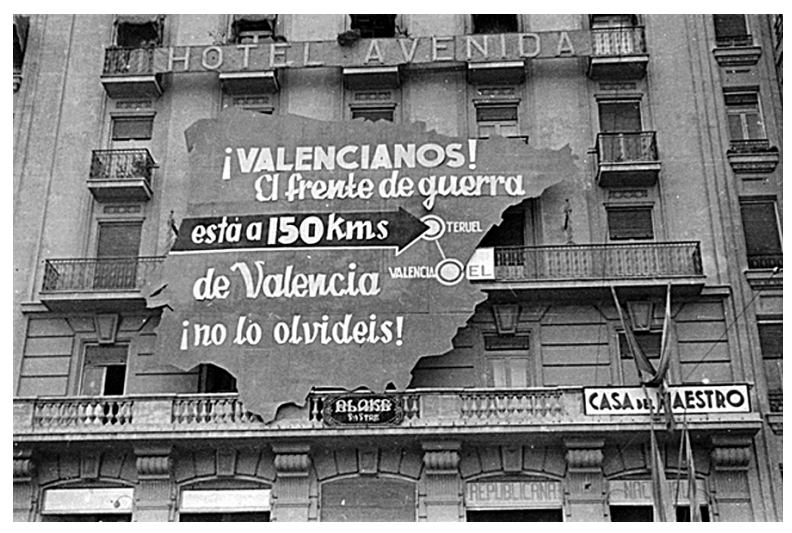

Fig. 4. Plaza de Emilio Castelar (actualmente del Ayuntamiento). Valencia, marzo-mayo 1937. Fotografías de Gerda Taro (C) ICP. 
Estaba con los soldados, y como un soldado del pueblo subía a Cabeza Grande. Con la risa de toda su juventud ardiente y alegre me mostró el trípode de su cámara-su fusil ${ }^{5}$.

La fotografía de Anna Seghers apareció publicada en la última página del periódico Ce Soir el domingo 11 de julio de 1937. Esta imagen formó parte de un fotomontaje en el que aparecían otras fotografías de los demás escritores durante sus intervenciones en las diferentes sesiones del congreso. El diseño de la página muestra un concepto periodístico muy novedoso, donde el grueso informativo es visual y se expone mediante una curiosa distribución de las imágenes fotográficas en la página (Fig. 5). El centro de la plana lo ocupa un retrato del francés Tristan Tzara y a su alrededor se organizan las imágenes de los demás escritores. Entre ellos se distingue a José Bergamín, André Malraux y Claude Aveline, Stephen Spender y Julien Benda, Álvarez del Vayo, Mijaíl Koltsov, Malcom Cowley, Alexéi Tolstói y Martin Anderson Nexo, cuyo rostro aparece en un formato circular que aporta un dinamismo extra a la página, principalmente estructurada mediante combinaciones formales trapezoides y asimétricas. La proporción escalar de la silueta de Seghers es moderadamente superior a la del resto de participantes. El tamaño de esta imagen y su ubicación orientan la atención lectora hacia el retrato de Seghers, la única mujer del grupo.

El análisis de la fotografía de Anna Seghers se ha realizado a partir del estudio comparado de dos originales: una copia obtenida por contacto del negativo original 24 x 36 mm ubicada en los Archivos Nacionales de París (ANP) y una copia de autor localizada en el Archivo Histórico de la sede del Partido Comunista Español en Madrid (PCE). La gerencia del Archivo Histórico del PCE nos ha confirmado que la copia examinada forma parte de un conjunto imágenes que llegó imprevistamente a las instalaciones del centro durante el periodo de dirección de Domingo Malagón, máximo responsable del archivo durante los años 80. Según Victoria Ramos, responsable en la actualidad, de la persona que confió el material a esta sede únicamente se sabe que fue un antiguo militante del PCE, y en relación con los documentos depositados, que son un conjunto de imágenes en soporte negativo y en papel relativos a la Guerra Civil Española. Entre esta documentación, examinada in situ, distinguimos 12 copias de época atribuibles a la fotógrafa Gerda Taro, aunque la mayoría de ellas no posee el sello de autor que las identifique. Este es el caso de la fotografía analizada, que no incluye el tampón "Photo Taro" en el reverso de la copia sino los distintivos del PCE, un número que cataloga la imagen y la grafía de la dirección del archivo atribuyendo erróneamente esta fotografía de Gerda Taro a Robet Capa (Fig. 6).

Paralelamente, los Archivos Nacionales de París (ANP) albergan ocho libretas de trabajo con aproximadamente 2.500 copias índice o por contacto -fotografías reveladas pero sin ampliar en formato $24 \times 36 \mathrm{~mm}$ - ordenadas por temas en varios cuadernos de escolar y pertenecientes a Robert Capa, Gerda Taro y David Seymour "Chim” sobre el tema de la Guerra Civil Española. La copia índice de la imagen de Anna Seghers se encuentra en el cuaderno $\mathrm{n}^{\circ} 1$, catalogada con el $\mathrm{n}^{\circ} 453$ y rodeada de las demás imágenes de la serie de

5 El mono Azul, 29 de julio de 1937. El periodista y poeta argentino Cayetano Córdova Iturburu dedicó a Gerda un segundo homenaje póstumo en esta misma publicación titulado "Adiós a Gerda Taro", El mono azul, 12 de agosto de 1937. 


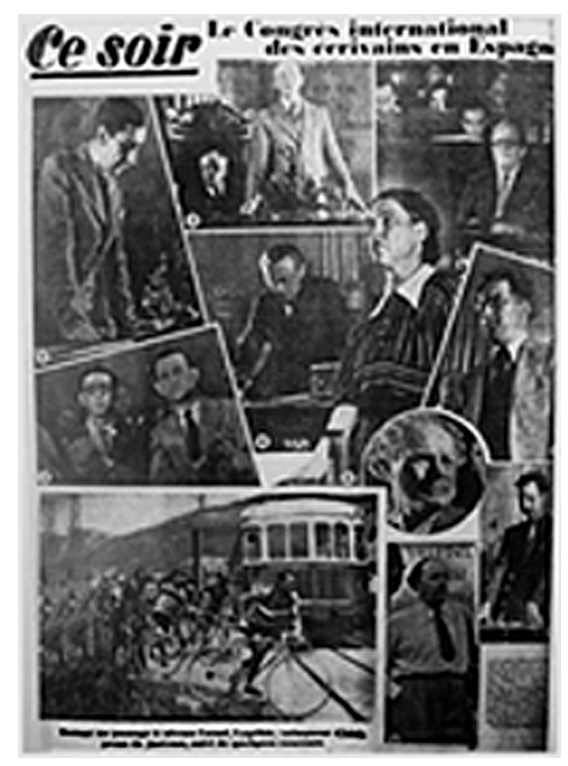

Fig. 5. Ce Soir, 11 de julio de 1937, última página.

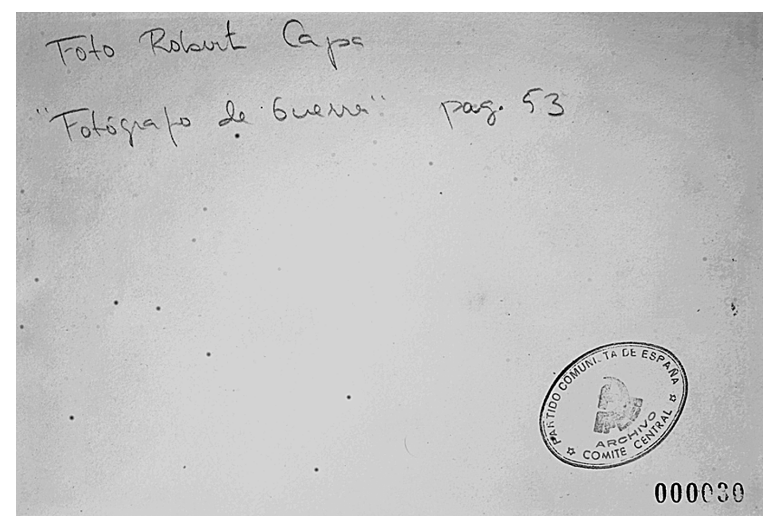

Fig. 6. Reverso de la fotografía de Anna Seghers realizada por Gerda Taro. Copia de época examinada en la sede del Archivo Histórico del PCE. La dirección del archivo atribuye erróneamente la autoría de esta imagen a Robert Capa.

los congresistas. Por tanto, el examen de la serie completa a la que pertenece esta imagen nos permite arrojar luz sobre la autoría de la misma; también profundizar en el método de trabajo de la pareja ${ }^{6}$, el sistema de ordenación de la obra y su posterior conservación, todas ellas cuestiones que afectan a la correcta atribución de algunas de estas imágenes.

${ }^{6}$ Pese a que la obra de "Chim" también forma parte de los fondos del ICP y los ANP sobre el tema de la Guerra Civil Española, el fotógrafo no se encontraba en Valencia durante la celebración del congreso. De ahí que el estudio únicamente profundice en las cuestiones que afectan a la obra de Taro y Capa. 


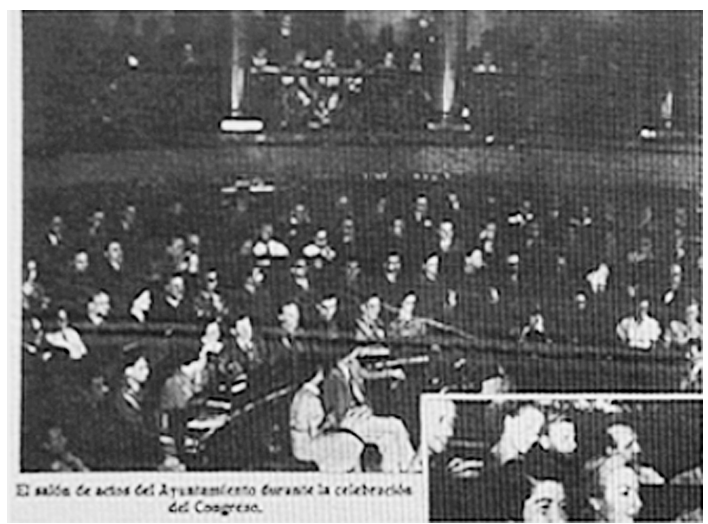

Fig. 7. Gerda Taro, vestida con falda y blusa blanca, aparece sentada en la primera fila del palco durante la inauguración del Segundo Congreso de Intelectuales Antifascistas. Revista Crónica, 18 de julio de 1937. Foto: Luis Vidal.

Fig. 8. Ce Soir, 22 de marzo de 1937.

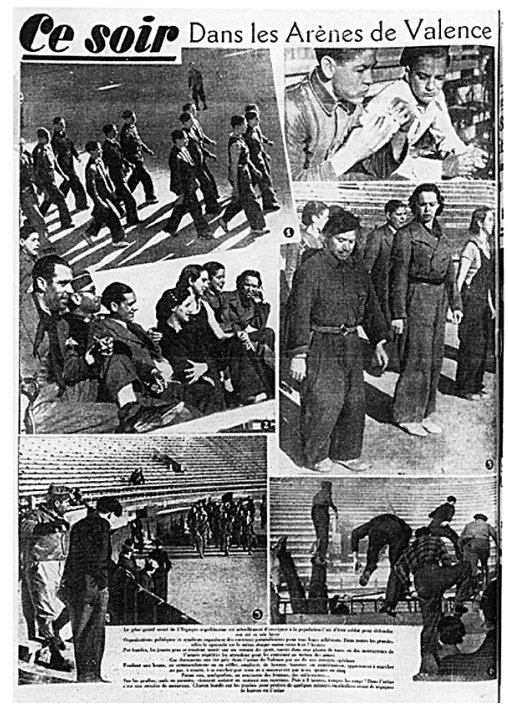

Todas las pruebas examinadas indican que Taro y Capa efectivamente trabajaron juntos en el Salón de Actos del Ayuntamiento de Valencia el día de la inauguración del congreso, ambos con cámaras de pequeño formato. Una imagen publicada en el semanal Crónica el 18 de julio de 1937 sitúa a Taro durante la inauguración del acto en la primera fila del palco (Fig. 7), y en el episodio n 19 "Brunete" de la serie documental España en guerra 1936-1939 aparece la fotógrafa reubicándose en el recinto con la cámara Leica. Por su parte, la asistente al congreso Elena Garro, en su texto Memorias de España 1937, describe a la pareja en el hemiciclo y recuerda especialmente a Gerda "tomando fotos a gran velocidad" (Garro, 1992: 23). Finalmente, el cuaderno de trabajo $\mathrm{n}^{\circ} 1$ (ANP) contiene una copia por contacto en la que aparece fotografiada Taro en el hemiciclo (Fig. 12). Dado el banco de imágenes en el que se encuentra esta copia, resulta obvio que fue Capa quien tomó esta fotografía de Gerda mientras trabajaba. Luego, la doble cobertura del acto con 
cámaras del mismo formato unido al método de clasificación común de las imágenes explican los problemas de autoría que presenta esta obra.

Además, la copia índice en la que aparece fotografiada Taro y la relativa a Anna Seghers muestran los mismos fallos de exposición en el libro Los Cuadernos de Guerra de Robert Capa (Serrano, 1987: 52-53), el único catálogo que reproduce las imágenes del fondo de París y, por tanto, la única fuente accesible a este contenido fotográfico, ya que una sentencia judicial por los derechos de autor impidió durante años el acceso al material original $^{7}$, y muchos de los negativos a los que pertenecen estas copias se dieron por perdidos durante décadas -hasta que reaparecieron en México. De este modo, durante años solo se pudo acceder al contenido de estas imágenes a través de su reproducción en el citado libro, donde los fallos de exposición que presentaban las dos imágenes apuntaban a que ambas pertenecían al mismo autor, es decir, a Capa, dado que en una de ellas aparecía Taro fotografiada. Sin embargo, cuando tuvimos acceso a las copias por contacto originales (ANP) definitivamente pudimos resolver el problema de autoría que presentaban algunas de estas imágenes, entre ellas la de Seghers, y profundizar en los motivos que lo habían podido alentar. Todo ello trataremos de explicarlo brevemente.

En primer lugar, los contactos originales que contienen los cuadernos depositados en París no son tiras únicas, sino copias índice independientes y ordenadas de un modo muy particular, lo que sugiere que las planchas por contacto se obtuvieron mediante un sistema diferente al método habitual del proceso $^{8}$. De hecho, el contacto relativo a la inauguración del congreso, fechado el día 4 de julio, está catalogado con el no 478 , mientras que el perteneciente a la fotografía de Seghers, realizada un día después, lo antecede en la ordenación serial su ubicación con el $n^{\circ} 451$. Luego, todo indica que las copias índice se ordenaron según una preselección no cronológica sino temática, o lo que es lo mismo, a partir de fotogramas independientes, obtenidos de diferentes películas y pertenecientes a distintos autores. Algo que, en definitiva, caracteriza la clasificación del conjunto general de fotografías de Capa, Taro y "Chim" sobre el tema de la guerra de España, toda ella ordenada por temas y no autores, según se ha podido comprobar a propósito de las series ubicadas en Nueva York, París, Madrid y México (Figs. 9, 10 y 11).

De este modo, el trabajo de estos fotógrafos ha quedado disuelto en un mismo conjunto de obra difícilmente atribuible al responsable de cada disparo, ya que se encuentra absolutamente entreverada y sin aparentes signos diferenciables. Pero, al acceder definitivamente a las libretas de trabajo de los fotógrafos (ANP), pudimos observar que las copias por contacto, aunque de nuevo independientes y aleatorias, no presentaban fallos de exposición, lo que indica que estos fallos técnicos solo afectan a las imágenes reproducidas por el historiador español para ilustrar su libro $^{9}$ y no a los originales.

7 En el año 2006 vistamos por primera vez el fondo de París (ANP) y no pudimos tener acceso al material original de Capa y Taro por este motivo. Fue en 2010, y gracias a la implicación personal de Isabelle Neuenschwander, directora del archivo, cuando pudimos acceder por primera vez al conjunto de fotografías de este archivo.

${ }^{8}$ Comúnmente, las copias índices se obtienen siguiendo el orden de un mismo rollo de película y por contacto directo con los negativos. Todo ello mediante varias tiras de alrededor de seis fotogramas cada una que se exponen al mismo tiempo de luz en la ampliadora.

9 Esto puede deberse al uso de una cámara compacta para la reproducción de los documentos. La modalidad automática de estas cámaras activa el flash, lo que afecta a la reproducción fidedigna de los fotogramas originales. 

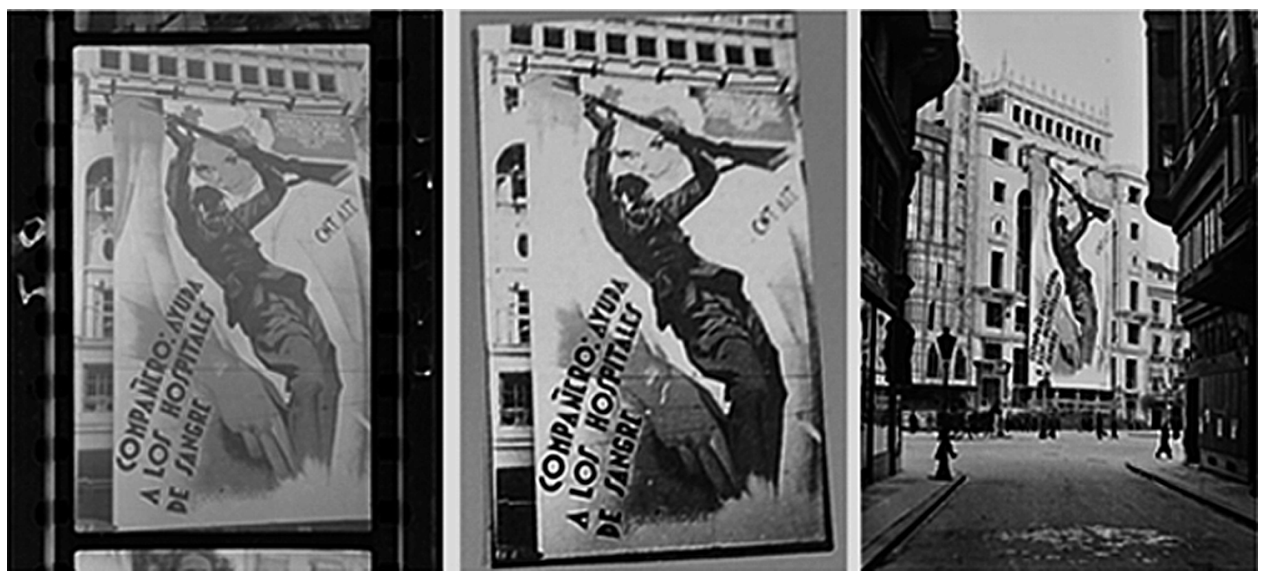

Figs. 9, 10 y 11. Negativo redescubierto en México en 2007, copia por contacto $\mathrm{n}^{\circ} 23$ del cuaderno $\mathrm{n}^{\circ} 7$ (ANP) y copia de negativo original en la sede del Archivo Histórico del Partido Comunista Español. De la serie de Gerda Taro sobre Valencia, marzo-mayo de 1937.
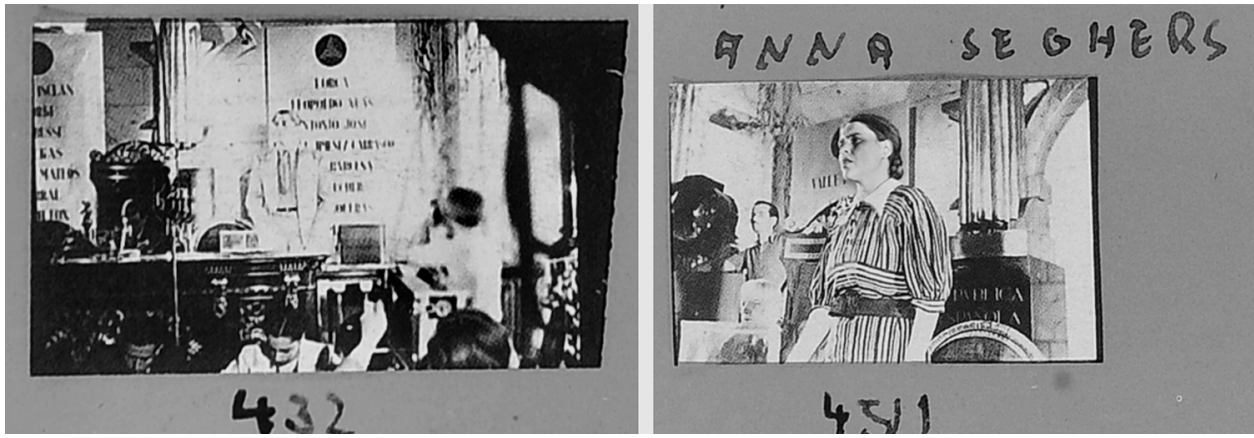

Figs. 12 y 13. Contacto $n^{\circ} 432$ del cuaderno $n^{\circ} 1$ (ANP), donde podemos distinguir a Gerda Taro, cercana al margen derecho del cuadro, fotografiando la intervención de un participante en el congreso. Esta fotografía realizada por Robert Capa el 4 de julio de 1937 determina el punto de vista de la fotógrafa, que a la vez coincide con el punto de la toma de Seghers (fig. 13).

Una razón de peso para atribuir la imagen analizada a Taro es su publicación en el periódico vespertino francés Ce Soir el domingo 11 de julio de 1937, esto es, cuando Capa ya ha prescindido de sus obligaciones contractuales con la publicación francesa y la fotógrafa todavía trabaja para la firma (Schaber, 2006: 226). Asimismo, al comparar la imagen en la que aparece fotografiada Taro de espaldas con la fotografía de Seghers puede apreciarse claramente cómo el punto de la toma de la segunda coincide plenamente con la articulación del punto de vista de la primera (Figs. 12 y 13). Pero el principal argumento que corrige este error de atribución de la imagen es la ausencia de Capa en Valencia el 5 de julio de 1937 (Whelan, 2003: 157), día en el que Seghers pronunció su discurso (Koltsov, 2009: 542). 
Por tanto, para finalizar con el nivel contextual, se confirma que se trata de una fotografía en blanco y negro realizada por Gerda Taro a una distancia aproximada de un metro y medio del referente con una cámara Leica IIIa y un objetivo $50 \mathrm{~mm} \mathrm{f/3,2} \mathrm{a} \mathrm{una} \mathrm{velocidad}$ de obturación aproximada a 1/60 de segundo y una abertura de diafragma oscilable entre f/9 y f/6.3. Para ello se utilizó una película negativa pancromática 35 mm 100 ASA. Algunos de estos aspectos técnicos de la imagen se comentarán más detalladamente en los diferentes niveles que quedan por explorar.

\subsection{Nivel morfológico}

En el nivel morfológico, y como descripción del motivo fotográfico, nos hallamos ante una fotografía protagonizada por Anna Seghers en la que, además de la escritora, aparecen dos sujetos varones ocupando la tribuna presidencial. Las tres figuras quedan enmarcadas por la decoración de la sala, engalanada para la ocasión. Tras la figura de la intelectual retratada distinguimos uno de los elementos simbólicos que presiden las sesiones del congreso. Se trata de un estandarte conmemorativo que hace referencia al escritor gallego Ramón María del Valle-Inclán, entonces ya fallecido.

El principal centro de interés de la fotografía es el rostro de Seghers. Los rasgos casi pueriles de la mujer contrastan con su gesto altivo. La iluminación directa que recibe el rostro provoca que la atención se dirija expresamente hacia su expresión, el centro de interés de la imagen. La ubicación y el gesto de la protagonista revelan que la instantánea ha sido realizada durante la oratoria de la escritora en el congreso. El uso de una película 100 ASA para un disparo de velocidad moderada y diafragma cerrado evita que podamos percibir el grano fotográfico como punto en sentido de materia expresiva. El centro de interés no coincide con el centro geométrico de la imagen.

El estampado del traje de Seghers y la estructura del recinto que la enmarca provoca un predominio de líneas verticales que contrasta con las líneas redondeadas de su figura femenina, los rostros de los sujetos que aparecen en la imagen y algunos elementos ornamentales de la sala. Por otro lado, se distingue un espacio organizado por cinco planos que se inician con un objeto fuera de foco ubicado en el margen inferior izquierdo del marco. La figura de Seghers ocupa el segundo término, y entre la mujer y la pared del fondo se ubican los otros dos sujetos: el primero con corbata y de cabello cano, ligeramente alejado de la mesa presidencial, y el segundo de pie y mirando a cámara. Ninguno de los sujetos fotografiados ocupa el centro exacto de la imagen. Este descentramiento provoca una leve sensación de imprecisión compositiva que queda compensada por el aplomo de la verticalidad arquitectónica del recinto y las líneas del vestido de la mujer.

La figura de Seghers actúa como la principal referencia organizadora del espacio fotográfico. El conjunto ofrece una más que aceptable nitidez general. La imagen presenta una amplia profundidad de campo que hace legible el recordatorio a Valle Inclán, ubicado en último término de la imagen. Este efecto se explica gracias al uso de un diafragma cerrado en combinación con la proximidad de la fotógrafa a la escena fotografiada. Por ello, se estima que Taro se encontraba a no más de un metro y medio de Seghers en el momento de la toma, una longitud muy similar al recorrido trazado entre la escritora y la pared del hemiciclo, último plano de la imagen. Por último, la textura general de la fotografía y la no deformación de los demás motivos nos remiten a las cualidades propias de una óptica 50 $\mathrm{mm}$ para paso universal. 
Como indican las pruebas gráficas examinadas, el sistema de iluminación de la sala se compone de seis cañones de luz de alta potencia dispuestos en ángulos estratégicos del salón. El encuadre de la fotografía sobre la Primera Sesión de Cortes celebrada en el Salón de Actos del Ayuntamiento valenciano días antes del Congreso incluye la misma disposición de los focos, donde pueden distinguirse cuatro luces de tungsteno dirigidas hacia la mesa presidencial (Fig. 14). Otra imagen paralela muestra la misma disposición de los focos que iluminan la zona presidencial y la gradería (Fig. 15). Luego, según la iluminación general de la escena y en relación con la profundidad de campo de la imagen, podemos establecer la velocidad de obturación en 1/60" y la apertura del diafragma en f/9, aproximadamente.

\subsection{Nivel compositivo}

En el estudio del nivel compositivo examinaremos cómo se relacionan los elementos anteriormente comentados desde un punto de vista sintáctico, es decir, conformando una estructura interna en la imagen. En este sentido, podemos señalar que se trata de una fotografía con profundidad en la que cuatro de los cinco planos de la imagen tienen foco. El peso de la fotografía queda desplazado hacia la izquierda, por lo que se advierte que la fotógrafa no ha tenido en cuenta el principio de la ley de tercios, pues ningún elemento significativo de la imagen se ubica en las zonas áureas de la composición. Esto sugiere rapidez en la ejecución de la toma.

La proliferación de formas estriadas del traje de Seghers forma un conjunto seriado de elementos que aportan ritmo a la composición. El contraste tonal extremo de la tela rayada, que también actúa como variable dinámica, se ve compensado por la ausencia de líneas oblicuas. La tensión compositiva viene establecida por este fuerte contraste tonal entre las líneas verticales y horizontales, en ocasiones interrumpidas por formas redondeadas. Sin embargo, la mirada de Seghers es el elemento que genera más tensión en la imagen dado que se dirige hacia el fuera de campo, al que la expresión de Seghers da un gran valor narrativo. Como siempre sucede, el formato fotográfico ha limitado el espacio fotografiado, y con ello ha dejado fuera de la imagen parte de la realidad. El fuera de campo es aquello que el espectador no ve, o lo que es lo mismo, aquello que el espectador cree que existe fuera del encuadre basándose en la información de lo que ve dentro del cuadro. No obstante, la expresión de Seghers y las crónicas de la época nos permiten recomponer este espacio invisible en la imagen.

Según informa el periodista J. Fernández Caireles en el semanal Crónica del 18 de julio de 1937, alrededor de unas veintiocho naciones estuvieron representadas en el Segundo Congreso de Escritores Antifascistas celebrado en Valencia. El principal cometido del acto fue deliberar sobre un mismo tema centrado en tres ideas generales: la libertad, la cultura y el papel del escritor en la sociedad. Las imágenes del reportaje que firma en esta publicación el fotógrafo Luis Vidal muestran el aforo del auditorio completo (Fig. 7). Junto a Seghers, el segundo día del congreso también hicieron uso de la palabra Julián Brenda, Johan Brouwer, Malcolm Kowley, González Tuñón, José Mancisidor y Alexéi Tolstói. Taro fotografió a Seghers mientras la escritora se dirigía a los asistentes con un discurso basado en la delicada situación de los que han perdido su patria y se han reencontrado en la lucha del pueblo español, según detalla el testimonio del periodista ruso de Pravda Mijaíl Koltsov (2009: 542). Luego, el de Seghers se adivina un discurso atendido y aplaudido dado el tema abordado y el grado de identificación de los demás intelectuales con las líneas del pensamiento de la oradora. La máxima tensionalidad de la fotografía vendría determi- 


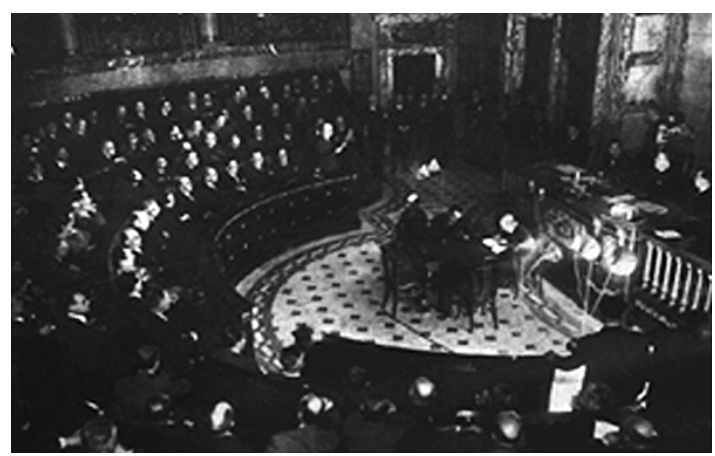

Fig. 14. Vista del sistema de iluminación general del Salón de Actos del Ayuntamiento de Valencia. Revista Crónica, 18 de julio de 1937 .

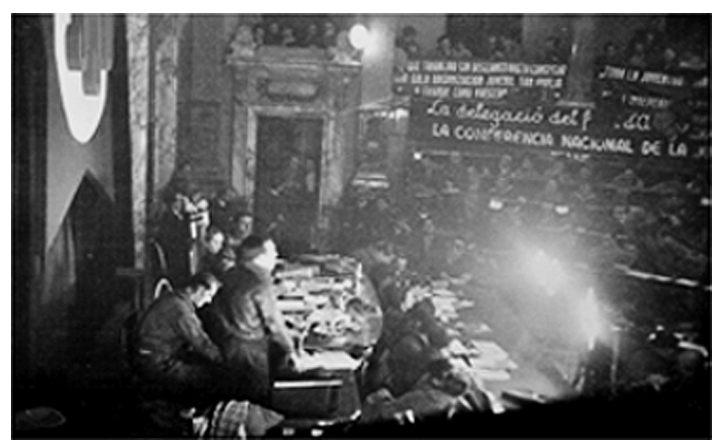

Fig. 15. Vista del sistema de iluminación de la tribuna presidencial del Salón de Actos del Ayuntamiento de Valencia (en Nothomb, 2001: 139).

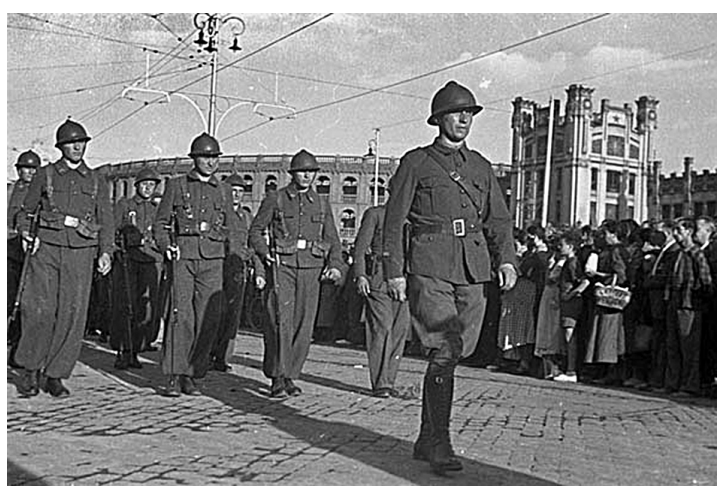

Fig. 16. Oficiales al paso de la Plaza de Toros y la Estación del Norte de Valencia durante el multitudinario cortejo fúnebre del general Pavol Lukács. Valencia, 12 de junio de 1937. Fotografía de Gerda Taro (C) ICP. Copia índice en el Cuaderno $\mathrm{n}^{\circ} 1$, contacto $\mathrm{n}^{\circ} 78$ (ANP). 
nada entonces por dos motivos fundamentales: por un lado, la empatía del público que acoge su comunicación, y por otro, la mirada que sobre Anna Seghers despliega Gerda Taro, quien enaltece al referente mediante el contrapicado de su fotografía. Se trata, por tanto, de una imagen que pretende promover significados muy específicos una vez insertada en los medios de comunicación escritos.

En el subapartado del espacio de la representación puede determinarse sin margen de error que se trata del interior del Salón de Actos del Ayuntamiento de Valencia. Los elementos arquitectónicos enriquecen el campo visual de la fotografía a partir de una amplia profundidad de campo que llega a su fin con los límites físicos del habitáculo. Pero, como acabamos de mencionar, uno de los aspectos que mejor definen el entorno se ubica precisamente en el fuera de campo, enunciado a través de las miradas de los sujetos fotografiados. En el caso de Seghers y el sujeto del tercer plano, ambas miradas se proyectan hacia la gradería, mientras el individuo del cuarto plano mira de soslayo a cámara. La dirección que proyecta esta última mirada conlleva a que no se estime un borrado absoluto de las huellas enunciativas en la imagen, pues esta figura nos interpele de forma explícita a través de la atención que el sujeto en cuestión ha prestado a la fotógrafa en el instante de la toma.

Por lo que respecta al tiempo de la representación, Gerda Taro fotografió a Anna Seghers mientras exponía sus ideas ante un público singular, docto y numeroso. Por tanto, no puede afirmarse que se trate de un instante de carácter irrepetible o decisivo, sino más bien prolongado en un tiempo concreto, delimitado por la duración del discurso de la escritora. Las copias índice paralelas a esta imagen examinadas en París (ANP) también descartan la idea de una construcción de la escena ex profeso. Finalmente, y como valoración global de la imagen en este nivel, puede decirse que se trata de una composición relativamente dinámica gracias a algunos aspectos que la construyen -como el ritmo, la tensión, la distribución de los pesos y el orden icónico. Asimismo, el momento fotografiado permite descartar la pose de los actantes, lo que confiere a esta imagen una alta dosis de verosimilitud y realismo muy útiles para su función informativa y propagandística.

\subsection{Nivel enunciativo}

Este último nivel del análisis pone el acento en los modos de articulación del punto de vista, una cuestión "que tiene consecuencias muy notables para profundizar en la ideología implícita de la imagen y la visión del mundo que transmite" (Marzal, 2007: 218). Todo indica, pues, que la mirada de la fotógrafa ha buscado un encuadre que enaltezca al referente a través del uso del contrapicado. La articulación del punto de vista se sitúa por debajo del ángulo de visión convencional, establecido a partir de la frontalidad propia del género documental de los años 30. El basculamiento de la cámara también se explica a partir de la ubicación que la fotógrafa ha decidido ocupar en la sala, lugar que dispone, en forma semicircular, diferentes alturas para cumplir con las exigencias de los actos que allí se celebran. En este caso, Taro se encuentra situada en el espacio escénico y la ponente fotografiada en el ábside o tribuna presidencial del hemiciclo, es decir, una de las zonas altas de la planta que ocupa. Esta disposición espacial, establecida a partir de las formas arquitectónicas cóncavas que numerosos edificios públicos han heredado del teatro griego, provoca un desnivel de altura que afecta al punto de vista de la toma. Y la elección de tal punto de vista, de acuerdo con el encuadre, no corresponde a una mirada testimonial sino a la voluntad propia del ente enunciativo. 
Por otra parte, el gesto de la protagonista contrasta de manera categórica con la expresión neutral de los otros dos sujetos que aparecen en la imagen. El rostro de Seghers desafía al público con la autodeterminación que llegamos a percibir a partir de la elevación del mentón y la mirada fruncida, en lontananza. A pesar del modo en el que la describe su colega Elena Garro, "con aire de institutriz bondadosa" (1992: 15), y la dulzura que le atribuye el periodista soviético Mijaíl Koltsov (2009: 542), la fotógrafa dista considerablemente de mostrarnos a una joven de carácter apocado. Más bien apunta hacia la dirección en la que Christa Wolf describe a Seghers para cada plano de su vida: "alemana, judía, comunista, escritora, mujer, madre. En cada una de estas palabras hay que pararse a reflexionar" (citado en Fuente, 2006: 365).

La expresión que ha capturado Taro subraya sobre todo lo demás el carácter de la fotografiada, como sucede con los demás ponentes que también han sido retratados para la misma serie. A rasgos generales, sus fotografías no hacen distinciones entre hombres y mujeres frente a determinados arquetipos -como los milicianos, los trabajadores, los intelectuales o las víctimas del fascismo. En este caso, y según hemos podido comprobar mediante el examen del conjunto de obra de la fotógrafa en diferentes centros de conservación, el arquetipo de la intelectual aparece representado en igualdad de condición que sus homólogos, del mismo modo que las milicianas fueron fotografiadas en la Plaza de Toros de Valencia instruyéndose en grupo junto a sus camaradas varones (Fig. 8). Incluso cuando las protagonistas de sus fotografías son mujeres con niños, aquello que Taro destaca del arquetipo de la madre es su espíritu antifascista mediante la captura de algún gesto revolucionario que las defina como tal (Fig. 17).

El encuadre y la articulación del punto de vista de la fotografía provocan que la atención espectorial incida sobre el arquetipo de la intelectual representado a través de la figura de Ana Seghers. La expresión de la escritora hace que la integración del sujeto en el entorno sea máxima, aunque la realidad del momento se encontrase débilmente relacionada con esta participación femenina en el ámbito de lo intelectual y lo público. El pronunciamiento de una mujer ante la máxima representación de la intelectualidad mundial suponía, en términos genéricos, un caso bastante inusitado para la realidad de la mujer del siglo pasado, y se presentaba aún más excepcional en el territorio español durante el año 1937. Aunque la vocación reformista de la Segunda República propuso conquistas insospechables para el colectivo femenino ${ }^{10}$, lo cierto es que, en la práctica, y salvo una minoría intelectualmente activa, la mujer española estuvo sobre todo entregada a las tareas domésticas y del campo, lo que retrotrajo casi toda su actividad a la invisibilidad de los espacios de la vida privada. Por tanto, y teniendo en cuenta el contexto de la imagen, esta fotografía también podría representar la nueva etapa que proponía el estado democrático español para la mujer en lo que a sus derechos sociales y políticos se refiere, aunque en la realidad se tratasen de avances más formales que efectivos dado el arraigo de las tradiciones españolas en la época.

${ }^{10}$ Las reformas emprendidas eliminaron una parte muy importante de la legislación discriminatoria que había mantenido la subordinación femenina en la política, el trabajo y la familia. En la Constitución de 1931 se indujo el principio de igualdad entre los sexos. Tras un debate en las Cortes, en que destacaron las dos únicas diputadas Clara Campoamor y Victoria Kent de un total de 465 miembros, se aprobó el sufragio femenino, medida que iba a permitir por primera vez en la historia de España que las mujeres accedieran a la política y tuvieran derecho a voto en las elecciones de 1933. 


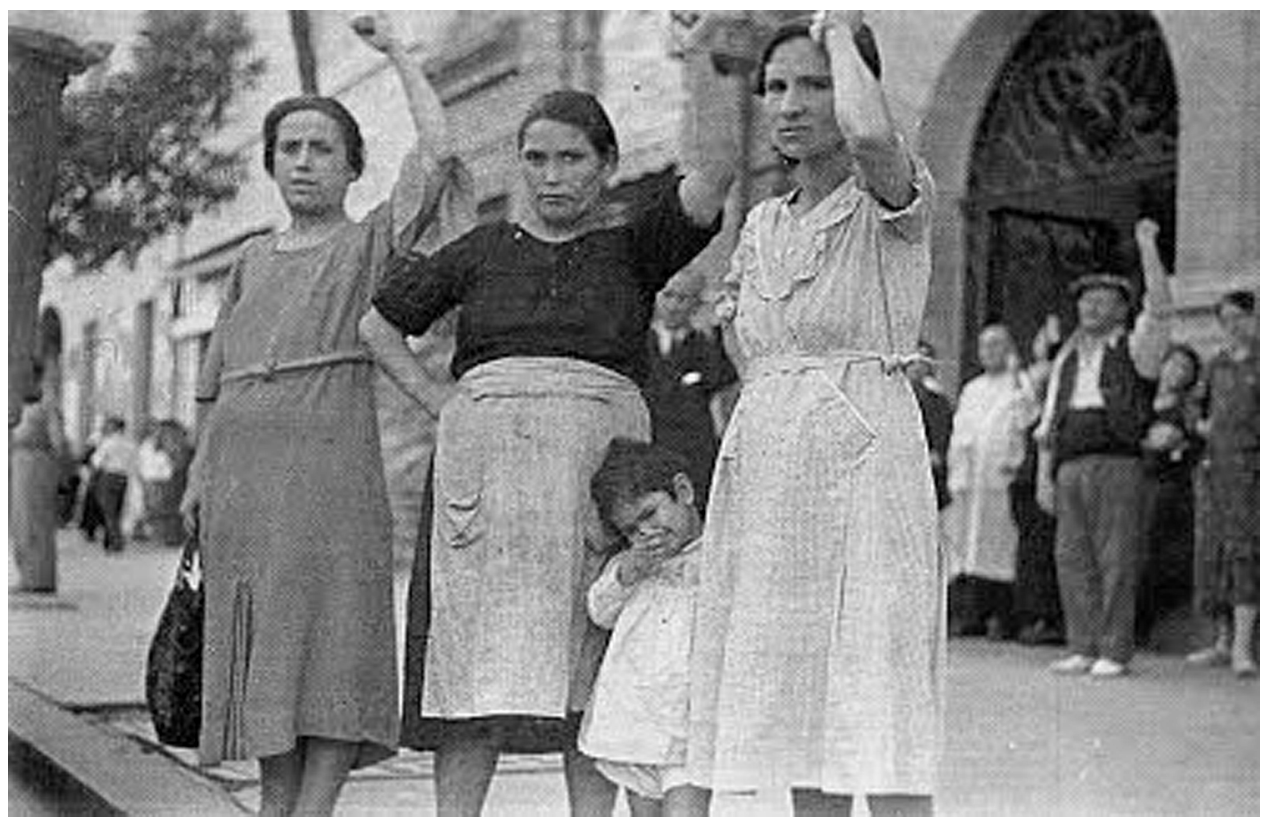

Fig. 17. Mujeres durante el cortejo fúnebre del general Lukács. Valencia, 12 de junio de 1937. Fotografía de Gerda Taro (C) ICP. Copia índice en el cuaderno n ${ }^{\circ}$, contacto n ${ }^{\circ} 246$ (ANP).

Ciertamente, en este plano los Estados Unidos y algunos países de Europa aventajaban en gran medida a la situación española ${ }^{11}$. Sin embargo, estas libertades recientemente adquiridas también se encontraron amenazadas por la depresión económica del 29, suceso que afectó limitando la continuidad del desarrollo profesional femenino iniciado durante la Primera Guerra Mundial (Nash y Tavera, 2003: 206). En el plano europeo, las recientes reformas que habían beneficiado al colectivo mermaron a consecuencia de la penetración de las ideologías fascistas y comunistas que, aunque rivales como doctrinas, coincidían en la medida de imponer el regreso de la mujer a sus funciones tradicionales ${ }^{12}$. Esta incertidumbre ante una regresión inminente para la mujer fue el tema a considerar por varias intelectuales antifascistas europeas, como la alemana Erika Mann, que planteaba a sus lectores "si debe escribir la mujer, escribir libros sin más, cuando cree que puede hacerlo"

${ }_{11}$ A parte de los sondeos estadísticos que así lo confirman, en el ámbito internacional existían publicaciones que defendían expresamente los derechos de la mujer, como los periódicos estadounidenses The Working Woman (1929-1935), Woman Today (1936-1937) y el británico Daily Worker, que incluía una columna diaria dedicada a la lucha política femenina.

${ }^{12}$ Stalin abolió en 1935 los aspectos más progresistas del Código Familiar Comunista. Se excluyeron los debates sobre la libertad sexual y la lucha por la igualdad de los sexos, y se impuso para las mujeres los valores tradicionales vinculados a su función de esposa y madre. En el caso de la doctrina nacionalsocialista, su política exigía la vuelta de la mujer alemana a sus funciones tradicionales, según la famosa convención de las tres k: kinder, kirche, und küche (hijos, iglesia, cocina), equivalentes a Dios, Patria y Familia. 
(Mann, 2002: 64). Aunque en la línea de la pluma de Mann la cuestión destila sarcasmo ${ }^{13}$, la escritora defiende que solo deberían escribir aquellas que fueran consecuentes con su periodo histórico, uno de los más críticos de la historia moderna,

Desde hace poco hay un nuevo tipo de escritora que a mí, por ahora, me parece el más prometedor: la mujer que escribe reportajes, ensayos, obras de teatro, novelas. No se confiesa, no pone su alma al descubierto en sus obras, deja su propio destino discretamente al margen, la mujer refiere en lugar de confesarse. Conoce el mundo, está al día, tiene humor y es avispada, y tiene la capacidad de ser opaca. Casi es como si tradujera: la vida en la literatura, no en la literatura excelsa, pero sí en una literatura útil, decente y a menudo digna de aprecio (Mann, 2002: 64).

Según esto, Anna Seghers se ajusta plenamente al arquetipo que Erika Mann reivindica. Seghers sintetizó las principales líneas de su pensamiento en la segunda sesión de la Asamblea de Valencia mediante una comunicación que sería posteriormente publicada en el n ${ }^{\circ}$ VIII de Hora de España, en agosto de 1937, como una más de la serie impresa que acreditó el excepcional encuentro celebrado en Valencia y cuyo principal objetivo fue el apoyo a la República en combate, no sólo contra las fuerzas golpistas interiores, sino también contra las potencias fascistas emergentes en Europa, de las que tanto Seghers como Taro ya habían sido víctimas en su Alemania natal.

Como Seghers, Taro también había sufrido las consecuencias del régimen de Hitler por su condición de judía. Ambas se habían exiliado en París y frecuentaban las mismas reuniones de la AEAR organizadas en el café Capoulade, centro de reunión de exiliados e intelectuales alemanes. Por tanto, resultan reveladores los puntos de contacto que unen a Taro y Seghers: dos mujeres jóvenes, alemanas, de origen judío y exiliadas en París que han viajado hasta España para prestar su apoyo a la República y contar en primera persona la experiencia de una guerra ajena. Estas razones nos llevan de nuevo a justificar las huellas que pueden reconocerse entre el sujeto enunciador y la instancia enunciativa, pues no sólo las marcas textuales de la fotografía apuntan hacia la presencia del autor en el propio texto visual -a través del tipo de composición, las variables dominantes, la articulación del punto de vista, etc.-, sino también mediante los rasgos de contigüidad que la fotógrafa comparte con el referente protagonista de su imagen. La fotografía sugiere, por tanto, que su autora pretende lograr una respuesta receptora eminentemente emotiva y promover la identificación con todo aquello que la imagen estimula.

La fotografía analizada remite a la modalidad del fotorreportaje. El aspecto rupturista de la imagen lo impulsa la figura protagonista en relación con el contexto y entorno que la enmarcan. En este sentido, la alteración de los criterios previamente comentados permite que la citada imagen se considere adelantada a su tiempo y pueda circunscribirse en una época más próxima a la actual en lo que al papel activo de la mujer en áreas extra domésticas se refiere. Por tanto, según lo expuesto a lo largo del análisis, esta fotografía incluye suficientes elementos como para determinar que se trata de una imagen que pretende despertar conciencias en varios niveles. Finalmente, en lo que respecta a las relaciones inter-

${ }^{13}$ La autora reprueba el autoanálisis en la obra literaria, rasgo que, según Mann, evoca al egocentrismo femenino. En este aspecto se aproxima a la idea de R. Margaret Higonnet cuando afirma: "uno de los clichés de la historia literaria es el de que los hombres escriben épica mientras las mujeres, diarios" (Usandizaga, 2007: 7). 


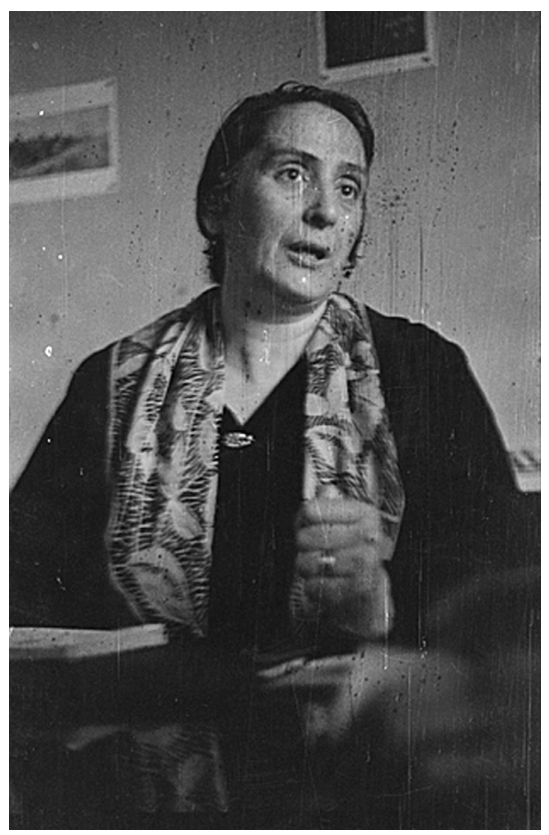

Fig. 18. Dolores Ibárruri La Pasionaria retratada por Gerda Taro. Valencia, primavera de 1937 (C) ICP.

Fig. 19. Gerda Taro fotografiada junto a los intelectuales en Madrid durante el mes de julio de 1937. Días después la fotoperiodista perdía la vida en calidad de corresponsal gráfica del periódico francés Ce Soir (C) ICP.

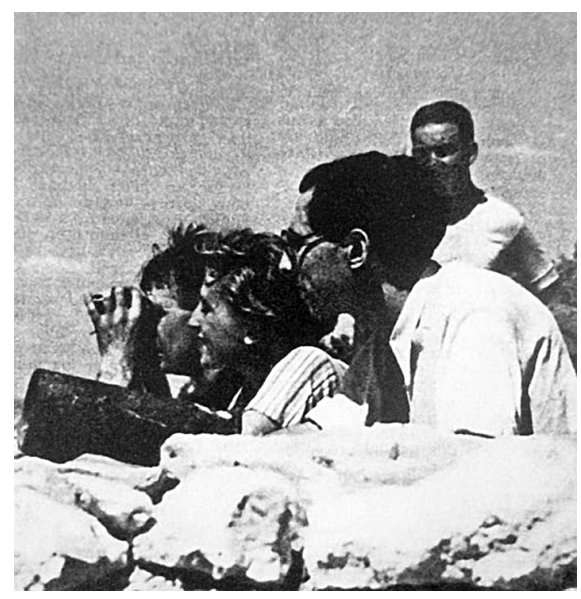

textuales que la fotografía propone, y para concluir con el apartado que cierra este último bloque, podemos añadir que la imagen remite a los retratos realizados por Taro en Valencia a Dolores Ibárruri, alias La Pasionaria, la más carismática propagandista de los republicanos durante la Guerra Civil (Fig. 18). También se reconoce la clara influencia de Robert Capa a partir de los retratos que el fotógrafo realizó a Leon Trotsky durante su conferencia en la Universidad de Copenhague el 27 de noviembre de 1932. 


\section{CONCLUSIONES}

El Segundo Congreso Internacional de Escritores para la Defensa de la Cultura fue la aportación más importante de la Alianza de Intelectuales Antifascistas al bando republicano durante la Guerra Civil Española. Fue inaugurado en Valencia el 4 de julio de 1937 y su principal cometido fue poner de relieve el impacto de la guerra sobre los intelectuales del mundo entero. Este congreso reunió a los más firmes valores intelectuales de la época, y con ellos a Gerda Taro y Robert Capa. Ambos documentaron juntos el acto de inauguración, lo que llevó a un reparto de tareas que sintetiza la estrategia metodológica del tándem Capa \& Taro, basada en una puesta en escena en la que cada fotógrafo aborda cuestiones concretas para obtener, en suma, un repertorio visual los más amplio posible del mismo acontecimiento. Las jornadas de intelectuales posteriores fueron documentadas únicamente por Taro, y el día 5 de julio de 1937 tomó la fotografía de la escritora alemana Anna Seghers en Valencia, objeto de este estudio. El análisis pormenorizado de la imagen ha permitido arrojar luz sobre aspectos importantes que afectan a la obra de Taro y Capa, entre ellos, el de la correcta atribución de sus imágenes.

Este trabajo también ha considerado algunas de las series que Taro realizó durante la primavera de 1937 en Valencia. En estas series destacan los detalles cotidianos de la vida en la ciudad y la representación de mujeres y hombres en igualdad de condición en la resistencia antifascista, lo que convierte estas fotografías en documentos pioneros dentro del fotoperiodismo de guerra.

Por último, los resultados del análisis revelan los numerosos puntos de contacto que la fotógrafa establece con el referente protagonista de su fotografía. En este caso, tanto el sujeto enunciador -la fotógrafa- como el de la instancia enunciativa -la intelectual- evocan a un modelo de nиеva mujer que incorpora elementos emancipadores y alusivos al modelo de mujer soviética. La mujer como constructora de progreso sobreviene en la figura de la intelectual extranjera que, como la fotógrafa que la retrata en Valencia, sede del gobierno republicano, ha viajado hasta la cuidad en plena guerra civil para ser de utilidad como mediadora en la lucha antifascista.

\section{REFERENCIAS BIBLIOGRÁFICAS}

ARROYO, Lorna B. (2010). Documentalismo técnico en la Guerra Civil Española. Inicios del fotoperiodismo moderno en relación a la obra fotográfica de Gerda Taro. Castellón de la Plana: Universidad Jaime I de Castellón.

AZNAR SOLER, Manuel (2007). "El Segundo Congreso Internacional de Escritores para la Defensa de la Cultura", La Guerra Civil en la Comunidad Valenciana, vol. XI. Valencia: Prensa Valenciana.

AZNAR SOLER, Manuel (2009). Valencia, capital cultural de la República (1936-1939), Valencia: Universidad de Valencia.

ECO, Umberto (1990). Los límites de la interpretación. Barcelona: Lumen.

FUENTE, Inmaculada de la (2006). La roja y la falangista, dos hermanas en la España del 36, Barcelona, Planeta.

KOLTSOV, Mijaíl (2009). Diario de la Guerra de España, Barcelona: Planeta.

GARRO, Elena (1992). Memorias de España 1937, Madrid: Siglo XXI. 
MANN, Erika (2002). Precisamente yo, Barcelona: Minúscula.

MARZAL, Javier (2007). Cómo se lee una fotografía. Interpretaciones de la mirada, Madrid: Cátedra.

MENDELSON, Jordana (2011). "Puesta en escena de una temática: la exploración de Gerda Taro de la visa cívica en Valencia, primavera de 1937”, La maleta mexicana. Madrid: La Fábrica.

NASH, Mary y TAVERA, Susanna (eds.) (2003). Las mujeres y las guerras. El papel de las mujeres en las guerras de la Antigüedad a la Contemporánea, Barcelona: Icaria.

NOTHOMB, Paul (2001). Malraux en España, Barcelona: Edhasa.

SCHABER, Irme (2006). Gerda Taro. Une photographe révolutionnaire dans la guerre d'Espagne, Paris: Du Rocher.

SCHABER, Irme, WHELAN, Richard y LUBBEN, Kristen (eds.) (2007). Gerda Taro. New York: ICP/ Steild.

SERRANO, Carlos (1987). Robert Capa. Cuadernos de Guerra. 1936-1939. Valencia: Alfons el Magnànim.

USANDIZAGA, Aránzazu (2007). Escritoras al frente: Intelectuales extranjeras en la Guerra Civil, San Sebastián: Nerea.

WHELAN, Richard (2003). Robert Capa. La biografía, Madrid: Aldeasa.

WHELAN, Richard (2007). This is war! Robert Capa at work. New York: ICP/STEIDL.

\section{Publicaciones periódicas (1937)}

Ce Soir el domingo 11 de julio de 1937.

Crónica, 18 de julio de 1937.

El Mercantil Valenciano, 6 de julio de 1937.

El Mono Azul, 29 de julio de 1937.

El Mono Azul, 12 de agosto de 1937.

Hora de España, nº VIII, agosto de 1937.

\section{Documentación audiovisual}

"Brunete", episodio 19 de la serie España en guerra, 1936-1939, dirigido por Pascual Cervera, producido por RTVE y emitido en 1987.

\section{Entrevistas y correspondencia}

Entrevistas y correspondencia postal con Trisha Ziff, directora del documental La Maleta Mexicana. 2009-2013.

Entrevista con Victoria Ramos (PCE). 2010.

Correspondencia con Kristen Lubben y Cynthia Young (ICP). 2008-2014.

Correspondencia postal con Isabelle Neuenschwander (ANP). 2008-2010. 
